\title{
Common celiacomesenteric trunk: a rare anatomic variation
}

\author{
Tronco único celíaco-mesentérico: uma variante anatômica rara
}

\author{
K. Sridhar Varma, ${ }^{1}$ Narendra Pamidi, ${ }^{2}$ Venkata R. Vollala ${ }^{2}$
}

\begin{abstract}
Common celiacomesenteric trunk, with the celiac and superior mesenteric arteries having a common origin from the aorta, is the least frequently reported anatomic variation of all abdominal vascular anomalies. Knowledge of variations concerning the celiac trunk and superior mesenteric artery are of great importance for both surgical approaches and angiographic examinations. Clinicians should keep in mind these variations to avoid complications.
\end{abstract}

Keywords: Common celiacomesenteric trunk, hepatomesenteric trunk, gastrosplenic trunk, Appleby procedure, clinical anatomy.

\section{Introduction}

Vitelline arteries are initially a number of paired vessels supplying the yolk sac. Gradually they fuse and form the arteries located in the dorsal mesentery of the gut. In the adult, they are represented by the celiac, superior mesenteric, and inferior mesenteric arteries. These vessels supply the derivatives of foregut, midgut, and hindgut, respectively. ${ }^{1}$ As anterior branches of the aorta, the celiac trunk and superior mesenteric artery are the most important as they supply the gastrointestinal tract. Celiac trunk usually arises from the aorta at the level of twelfth thoracic vertebra and after a short course, divides into left gastric, common hepatic and splenic arteries. The common hepatic artery, after its origin from the celiac trunk, runs downwards and to the right until it reaches the first part of duodenum. At the upper border of the first part of duodenum, it divides into hepatic artery proper and gastroduodenal arteries, usually giving off a right gastric branch before its termination. The hepatic artery proper ascends in the right free margin of lesser omentum lying anterior to the portal vein and on the left side of the bile duct. It divides into

\section{Resumo}

O tronco único celíaco-mesentérico, com as artérias celíaca e mesentérica superior tendo uma origem comum a partir da aorta, é a variante anatômica menos reportada dentre todas as anomalias vasculares abdominais. Conhecer as variantes do tronco celíaco e da artéria mesentérica superior é de grande importância tanto para abordagens cirúrgicas quanto para exames angiográficos. É importante que os médicos tenham em mente essas variantes a fim de evitar complicações.

Palavras-chave: Tronco único celíaco-mesentérico, tronco hepatomesentérico, tronco gastroesplênico, operação de Appleby, anatomia clínica.

right and left hepatic arteries at or near the porta hepatis. Celiac trunk supplies the liver, stomach, pancreas and superior part of duodenum.

The superior mesenteric artery is the second ventral branch of the abdominal aorta. It runs anterior to the third part of the duodenum and enters the mesentery of the small intestine. Its normal branches include inferior pancreaticoduodenal, jejunal, ileal, ileocolic, right colic and middle colic arteries. The superior mesenteric artery supplies a large part of the intestine from the descending part of the duodenum to the mid-transverse colon. Variations of these arteries and their relationship to surrounding structures are, therefore, of particular importance from a surgical perspective..$^{2-5}$

\section{Case report}

The present variation was observed in a 60 -year-old male cadaver during dissection classes for medical undergraduates. The celiac trunk and superior mesenteric artery were noted to have common anatomic origin from the aorta (Figure 1). This kind of variation was referred in the lite-

\footnotetext{
1. Department of Anatomy, M.R. Medical College, Gulbarga Karnataka, India.

2. Department of Anatomy, Melaka Manipal Medical College (MMMC), International Centre for Health Sciences, Manipal, India.

No conflicts of interest declared concerning the publication of this article.

Manuscript received Sep 11 2008, accepted for publication Apr 292009.

$J$ Vasc Bras. 2009;8(3):271-273.

Copyright @ 2009 by Sociedade Brasileira de Angiologia e de Cirurgia Vascular
} 


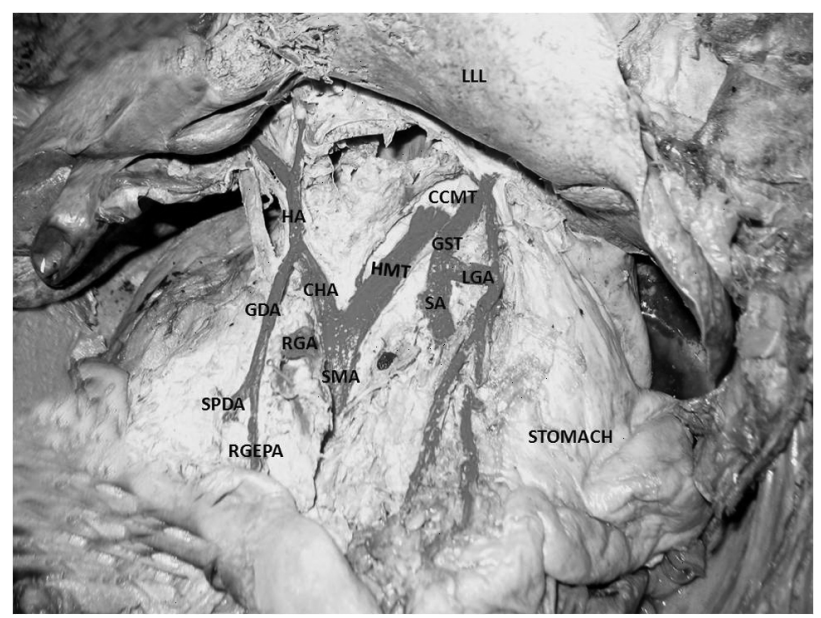

$\mathrm{LLL}=$ left lobe of the liver; CCMT = common celiacomesenteric trunk; $\mathrm{HA}=$ hepatic artery; GDA = gastroduodenal artery; $\mathrm{CHA}=$ common hepatic artery; RGA = right gastric artery; $\mathrm{SMA}=$ superior mesenteric artery; SPDA = superior pancreaticoduodenal artery; RGEPA = right gastroepiploic artery; HMT $=$ hepatomesenteric trunk; GST = gastrosplenic trunk; LGA = left gastric artery; $\mathrm{SA}=$ splenic artery.

Figure 1 - Dissection of the abdomen showing the common celiacomesenteric trunk and its branches

rature as common celiacomesenteric trunk. In the present case, the common celiacomesenteric trunk was divided into hepatomesenteric and gastrosplenic trunks. The gastrosplenic trunk was divided into left gastric and splenic arteries. The hepatomesenteric trunk was divided into common hepatic and superior mesenteric artery. The superior mesenteric artery was running down, deep to the neck of the pancreas to supply the midgut. The common hepatic artery gave off right gastric and gastroduodenal arteries before it continued as hepatic artery. The gastroduodenal artery was divided into superior pancreaticoduodenal and right gastroepiploic arteries.

\section{Discussion}

Celiac and superior mesenteric arteries having a common origin from the aorta accounts for less than $1 \%$ of all abdominal vascular anomalies, and it is estimated to have an incidence of $0.25 \% .{ }^{6-8}$ Superior mesenteric artery is developmentally considered as a part of the celiac complex and it follows that variations in the superior mesenteric artery are related to the celiac trunk. ${ }^{9}$ The anatomical variations of these vessels are due to developmental changes in the ventral splanchnic arteries. In some cases, the celiac trunk will be compressed (Dunbar's syndrome) by an overly large median arcuate ligament of the diaphragm.
So, in the present case, the chances of compression of common celiacomesenteric trunk by median arcuate ligament and the aortic opening are high, because of its large size and its position. During the evaluation of the celiac trunk compression syndrome, the existence of a common celiacomesenteric trunk should be kept in mind. ${ }^{10}$ Knowledge of the common hepatic artery arising from superior mesenteric artery is important for surgeons performing pancreaticoduodenectomy. ${ }^{2}$ Celiac trunk is known for variations: all the three of its branches might come from the abdominal aorta as independent branches or it might give rise to additional branches such as the superior mesenteric artery and inferior phrenic arteries. In a study by Nayak, the celiac trunk (gastro-splenico-phrenic trunk) divided into inferior phrenic trunk, left gastric and splenic arteries. The inferior phrenic trunk divided into right and left inferior phrenic arteries. The common hepatic artery took its origin from an hepatomesenteric trunk and passed behind the portal vein and bile duct. ${ }^{11}$

Knowledge about the variations of celiac trunk and superior mesenteric artery are of extreme clinical importance in the areas of the Appleby procedure, ${ }^{12}$ laparoscopic surgery, and radiological procedures in the upper abdomen, and should be kept in mind by clinicians to avoid complications. Prior knowledge about the anomalous branching pattern of celiac trunk and superior mesenteric artery is essential to successfully accomplish surgical, oncologic, or interventional procedures including lymphadenectomy around a hepatosplenomesenteric trunk, aortic replacement with reimplantation of the trunk, or chemoembolization of liver malignancies, all of which can potentially create significant morbidity because of the large visceral territory supplied by a single vessel. ${ }^{13}$

\section{Conclusion}

The case report provides information about variations in the origin and branching patterns of celiac trunk and superior mesenteric artery and their clinical importance.

\section{References}

1. Sadler TW. Langman's medical embryology. 10th ed. Baltimore: Williams and Wilkins; 2008.

2. Nayak S. Hepatomesenteric trunk and gastro-splenicophrenic trunk. Int J Anat Variat. 2008;1:2-3.

3. Vandamme JP, Bonte J. The branches of the coeliac trunk. Acta Anat. 1985;122:110-4.

4. Williams PL, Bannister LH, Berry MM, et al. Gray's anatomy. London: Churchill Livingstone; 1995. 
5. Kahraman G, Marur T, Tanyeli E, Yyldyrym M. Hepatomesenteric trunk. Surg Radiol Anat. 2001;23:433-5.

6. Michels NA, Siddharth P, Kornblith PL, Parke WW. Routes of collateral circulation of the gastrointestinal tract as ascertained in a dissection of 500 bodies. Int Surg. 1968;49:8-28.

7. Michels NA. Blood supply and anatomy of the upper abdominal organs with a descriptive atlas. Philadelphia: Lippincott; 1955.

8. Fontaine R, Pietri J, Tongio J, Negreiros L. Angiographic study of the anatomical variations of the hepatic arteries based on 402 specialized examinations. Angiology. 1970;21:110-3.

9. Cicekcibasi AE, Uysal II, Seker M, Tuncer I, Büyükmumcu M, Salbacak A. A rare variation of the coeliac trunk. Ann Anat. 2005;187(4):387-91.

10. Cavdar S, Sehirli U, Pekin B. Celiacomesenteric trunk. Clin Anat. 1997;10:231-4.
11. Nayak S. Common celiaco-mesenterico-phrenic trunk and renal vascular variations. Saudi Med J. 2006;27:1894-6.

12. Kimura W, Han I, Furukawa Y, et al. Appleby operation for carcinoma of the body and tail of the pancreas. Hepatogastroenterology. 1997;44:387-93.

13. Losanoff JE, Millis JM, Harland RC, Testa G. Hepatospleno-mesenteric trunk. J Am Coll Surg. 2007;204:511.

Correspondence:

Narendra Pamidi

Department of Anatomy

Melaka Manipal Medical College (Manipal Campus)

International Centre for Health Sciences

576104 - Manipal, Karnataka - India

Tel.: +91 (820) 292.2519, ext. 22642

Fax: +91 (820) 257.1905

E-mail: pommidi_narendra@yahoo.co.in 